\title{
Investigating the Relationship between Talent Management Strategy and Career Path of Principals of Schools in Shahr-e-Kord
}

\author{
Zahra Gholipour \\ MA in Educational Administration, Shahrekord Islamic Azad University \\ ShahreKord, Iran
}

Seyed Ali Siadat (Corresponding author)

Associate professor of University of Isfahan

Isfahan, Iran

E-mail: s.a.siatdat@edu.ui.ac.ir

Mohammad Taghi Mahmoudi

Assistant professor of Shahrekord Islamic Azad University

ShahreKord, Iran

Received: August 29, 2015 Accepted: September 18, 2015 Published: February 12, 2016

doi:10.5296/ire.v4i1.9007

URL: http://dx.doi.org/10.5296/ire.v4i1.9007

\begin{abstract}
The aim of the present study is to investigate the relationship between talent management strategy and career path in principals of schools in Shahr-e-Kord. The study is a descriptive-correlational one and its population includes all principals of high schools in Areas 1 and 2 of Shahr-e-Kord equal as 103 individuals in the academic year 2014-2015. A number of 81 principals were selected as participants via the simple random sampling and using Chochrane's formula. To measure talent management, the Sweem standard questionnaire and to measure career path, the Schaufeli standard questionnaire were used. The reliability coefficients for the questionnaires were calculated using Chronbach's alpha coefficients as 0.85 and 0.84 respectively. Data analysis was conducted using Pearson
\end{abstract}


correlation coefficient and regression coefficient by SPSS. The results indicated that talent management strategy has a positive and significant correlation with principals' career path of principals of schools in Shahr-e-Kord. In addition, there is a direct and significant correlation between components of communication, performance management, training the staff and in acknowledgment of individuals with career path.

Keywords: career path, talent management strategy, communication, rewarding and acknowledging, high school

\section{Introduction}

Human investment and promotion of the quality of workforces are among main and basic rounds and ways of promotion, productivity, development, and growth of organizations. Therefore, organizations for retaining their talented and knowledge-based staff and increasing their efficacy and efficiency should pay particular attention to important factors affecting the staff's behaviors. The main psychological construct having an outstanding role in increasing individuals' performance is Work Engagement (Tajjalizadeh, 2013).

Work Engagement is defined as a positive mental state toward jobs which is described with powerful features at work, being engaged in work, and being attracted to work. It refers to a stable and comprehensive psychological state instead of a temporary and specific state (Schaufeli, 2007 as cited in Nouri et al., 2010).

Attraction refers to the degree of a person's concentration and saturation in his or her work. In this condition, the person gets engaged in his work stubbornly and this experience is very joyful for him. In the dimension of the strength, the person exerts significant efforts in line with doing work and has more persistence in difficult situations. The staff enjoying higher strength, in case of the occurrence of problems and interpersonal conflicts shows more resistance (Salanova, Agut, \& Peiro, 2005). The third dimension of engagement is being devoted to work which is identified with an individual's severe psychological involvement in work and is a combination of feelings of significance, engagement and challenge. This dimension has a lot in common with the concept of Job Involvement and refers to a degree to which the individual considers himself involved in job (Tajjalizadeh, 2013).

Bhatnagar knows talent management as an instrument for improving the process of employment and development of individuals for accessing skills and capabilities required for facing current needs of organizations (2007). Talent management is a set of processes designed for guaranteeing that the staff are appropriately flowing in their organizations from one job into another (Cheloha \& Swain, 2005). Talent management strategy includes components such as 1) performance management, 2) training the staff, 3). Acknowledging and rewarding individuals, 4) open space and atmosphere in organizations and 5) communications (Sweem, 2009).

The necessity of identifying talent management strategy by organizations and the needs of organizations to engagement and enthusiasm to doing work, the investigation of the relationship between talent management strategy and career path of principals can provide strategies of the expansion of the perspective in optimal management of human resources for 
us. Since education is as expansive as all individuals of the society; therefore, it should exert all of its effort for providing services. It seems that one of the techniques necessary for attaining this objective is to have talented and enthusiastic managers. Accordingly, the present study is to investigate the relationship of talent management strategy and career path of principals of high schools in Shahr-e-Kord.

\section{Methodology}

\subsection{Research Method}

The present study is an applied one and its design is descriptive. It is correlation in terms of the type of data and strategies.

\subsection{Population}

The population includes all high school principals of Areas 1 and 2 of Shahr-e-Kord equal as 103 individuals in the academic year 2014-2015. Fifty four of them are women and 49 of them are men.

\subsection{Sample, Sampling Method, and Sample Size}

The sampling method is the simple random sampling. Among all principals of the high schools of Areas 1 and 2 of Shahr-e-Kord as 103 individuals, a number of 81 principals were selected using Chochrane's formula and 78 valid questionnaires were returned.

\subsection{Measuring Instruments}

1) The talent management questionnaire: the Sweem's Talent Management Questionnaire including 30 items, investigates 5 components of communications, training the staff, rewarding and acknowledging, performance management, open atmosphere and culture. Sweem (2009) calculated the validity of the questionnaire based on Kendall's tau-b as 0.74 . In addition, the reliability of the questionnaire was obtained as 0.88 using Chronbach's alpha. In the present study, to evaluate the reliability of the questionnaire, Chronbach's alpha was employed and its coefficient was obtained as 0.85 .

2) The career path questionnaire: this questionnaire was designed by Schaufeli et al. (2006) which includes 17 items and investigates three components of strength (professional energy), attraction (professional fascination), and devotion (dedication). Schaufeli et al. (2006) calculated the validity coefficient using Chronbach's alpha as 0.88 and using split-half as 0.80 and its reliability as 0.71 via Kendall's tau-b. In the present study, to re-evaluate the reliability of the questionnaire, it was calculated by Chronbach's alpha and its coefficient was obtained as 0.84 .

\subsection{Data Analysis}

To analyze the data, regression coefficient and Pearson correlation coefficient were used. 


\section{Research Findings}

Table 1. The results of Pearson correlation coefficient of the relationship of talent management and career path of principals in the high school of Shahr-e-Kord

\begin{tabular}{ccccc}
\hline Resource & F & r & Coefficient of determination & Sig. \\
\hline Talent management and career path & 78 & 0.37 & 0.13 & 0.001 \\
\hline
\end{tabular}

According to the obtained results, the r-observed at the level $\mathrm{p} \leq 0.05$ indicates the positive and significant correlation between talent management and career path of high school principals. In other words, the existence of talent management in education results in the increase in the engagement and enthusiasm in the career path of high school principals of Shahr-e-Kord.

Table 2. The results of Pearson correlation coefficient of the relationship of performance management and career path of principals in the high school of Shahr-e-Kord

\begin{tabular}{lcccc}
\hline Resource & F & r & $\begin{array}{c}\text { Coefficient of } \\
\text { determination }\end{array}$ & $\begin{array}{c}\text { Sig. } \\
\text { Performance management with strength (professional energy) }\end{array}$ \\
Performance management with attraction (professional fascination) & 78 & 0.37 & 0.13 & 0.001 \\
Performance management with devotion (dedication) & 78 & 0.22 & 0.02 & 0.05 \\
\hline
\end{tabular}

According to the obtained results, the r-observed at the level $\mathrm{p} \leq 0.05$ indicates the positive and significant correlation between performance management and strength (professional energy), attraction (professional fascination), and devotion (dedication) of high school principals. In other words, the existence of talent management in education results in the increase in the strength (professional energy), attraction (professional fascination), and devotion (dedication) of high school principals of Shahr-e-Kord.

Table 3. The results of Pearson correlation coefficient of the relationship of training the staff and career path of principals in the high school of Shahr-e-Kord

\begin{tabular}{llllc}
\hline Resource & F & r & Coefficient of determination & Sig. \\
\hline training the staff with strength (professional energy) & 78 & 0.40 & 0.16 & 0.001 \\
training the staff with attraction (professional fascination) & 78 & 0.39 & 0.15 & 0.05 \\
training the staff with devotion (dedication) & 78 & 0.49 & 0.24 & 0.002 \\
\hline
\end{tabular}

According to the obtained results, the r-observed at the level $\mathrm{p} \leq 0.05$ indicates the positive and significant correlation between training the staff and strength (professional energy), attraction (professional fascination), and devotion (dedication) of high school principals. In other words, the existence of training the staff in education results in the increase in the strength (professional energy), attraction (professional fascination), and devotion (dedication) of high school principals of Shahr-e-Kord. 
Table 4. The results of Pearson correlation coefficient of the relationship of communications and career path of principals in the high school of Shahr-e-Kord

\begin{tabular}{lllcc}
\hline Resource & F & r & Coefficient of determination & Sig. \\
\hline communications with strength (professional energy) & 78 & 0.37 & 0.13 & 0.001 \\
communications with attraction (professional fascination) & 78 & 0.22 & 0.04 & 0.05 \\
communications with devotion (dedication) & 78 & 0.35 & 0.11 & 0.002 \\
\hline
\end{tabular}

According to the obtained results, the r-observed at the level $\mathrm{p} \leq 0.05$ indicates the positive and significant correlation between communications and strength (professional energy), attraction (professional fascination), and devotion (dedication) of high school principals. In other words, the existence of communications in education results in the increase in the strength (professional energy), attraction (professional fascination), and devotion (dedication) of high school principals of Shahr-e-Kord.

Table 5. The results of Pearson correlation coefficient of the relationship of acknowledging and rewarding individuals and career path of principals in the high school of Shahr-e-Kord

\begin{tabular}{|c|c|c|c|c|}
\hline Resource & $\mathrm{F}$ & $\mathrm{r}$ & $\begin{array}{l}\text { Coefficient of } \\
\text { determination }\end{array}$ & Sig. \\
\hline $\begin{array}{l}\text { acknowledging and rewarding individuals with strength (professional } \\
\text { energy) }\end{array}$ & 78 & 0.31 & 0.10 & 0.005 \\
\hline $\begin{array}{l}\text { acknowledging and rewarding individuals with attraction (professional } \\
\text { fascination) }\end{array}$ & 78 & 0.45 & 0.18 & 0.001 \\
\hline acknowledging and rewarding individuals with devotion (dedication) & 78 & 0.46 & 0.19 & 0.001 \\
\hline
\end{tabular}

According to the obtained results, the r-observed at the level $\mathrm{p} \leq 0.05$ indicates the positive and significant correlation between acknowledging and rewarding individuals and strength (professional energy), attraction (professional fascination), and devotion (dedication) of high school principals. In other words, the existence of acknowledging and rewarding individuals in education results in the increase in the strength (professional energy), attraction (professional fascination), and devotion (dedication) of high school principals of Shahr-e-Kord.

Table 6. the results of Pearson correlation coefficient of the relationship of open atmosphere and culture and career path of principals in the high school of Shahr-e-Kord

\begin{tabular}{cllc}
\hline Resource & F & r & Coefficient of determination \\
\hline $\begin{array}{c}\text { open atmosphere and culture with strength (professional energy) } \\
\text { open atmosphere and culture with attraction (professional } \\
\text { fascination) }\end{array}$ & 78 & 0.11 & 0.35 \\
$\begin{array}{c}78 \\
\text { open atmosphere and culture with devotion (dedication) }\end{array}$ & 78 & 0.04 & 0.71 \\
\hline
\end{tabular}

According to the obtained results, the r-observed at the level $p \leq 0.05$ does not indicate the positive and significant correlation between open atmosphere and culture and strength 
(professional energy), attraction (professional fascination), and devotion (dedication) of high school principals.

\section{Discussion and conclusion}

Findings regarding the relationship between talent management and career path of principals of high schools in Shahr-e-Kord indicated that there is a positive and significant correlation between talent management and career path of principals of high schools in Shahr-e-Kord. In other words, the existence of talent management in education results in the increase in the engagement in career path of principals of high schools in Shahr-e-Kord. Career path analysis causes that individuals be aware of their own tasks and responsibilities and try to use their talent and power in line with increasing their own job knowledge and improve their own performance. Accordingly, talent management tries to collect job knowledge, improves individuals' job and organizational performance. Therefore, talent management and career path analysis move in line with job and organizational performance and can have a close relationship with each other. In the studies conducted by Bethkeet al. (2010), Stewart and Hart (2010), Iles et al. (2009), Hosseini (2011), Ghaffari et al. (2013), Ashegh Hosseini Mehravani et al. (2014), talent management has been reported as a factor for improving the performance of human resources management.

In the single-loop learning model, the increase in the efficacy of the organization in available organizational norms is effective when managers have particular commitment to organizational learning and the increase in job and organizational knowledge, and develop continuously organizational and job training needed by the staff in all organizational levels and can manage talents of organizations. Accordingly, when talent management develops, and individuals attain job and organizational knowledge they can be put in their own career path because they feel satisfied more in their organizations. This issue has been reported in the study of Guy et al. (2009) which talent management results in the enhancement of sense of satisfaction in the staff.

Findings regarding the relationship between performance management, training, communications, and rewarding and acknowledging the staff and career path of principals of high schools in Shahr-e-Kord indicated that there is a positive and significant correlation between performance management with strength (professional energy), attraction (professional fascination), and devotion (dedication) of high school principals. In other words, the existence of performance management, training, communications, and rewarding and acknowledging the staff result in the increase in the strength (professional energy), attraction (professional fascination), and devotion (dedication) of high school principals of Shahr-e-Kord.

According to the modern model, talent management is a new approach which can provide a transformation in human resources management and develop new job knowledge in organizations. Accordingly, human resources are the main capital in each organization and are present actively and dynamically in organizations. They can result in the improvement in individuals' performance. Therefore, the results of the present study are consistent with the modern model of talent management. Armstrong (2000) considers performance management 
as a strategic and integrated method which can provide sustainable success for organizations via improving their staff's performances and also via developing individuals' capabilities and those of teams (Arabi, 2014).

In the theory of open career path and ultra-competencies of Hall, this issue has been mentioned that a lot of passengers of career path enjoy the independency of such career paths, but they soon learn that in such paths, there is no external support. To cope with such insecurity, individuals should have the sense of strength and this is when organizational communications among them can help them. Therefore, the results of the present study are consistent with the theory of open career path and ultra-competencies of Hall.

Reward management covers strategies, policies and processes which guarantees the staff's values. Reward refers to each kind of receipt and value which the employer pays to individuals for doing something. The aim of designing the appropriate reward system in organizations is to attract and retain competent staff and also increase their motivation to be in their own career path and attain new job and organizational knowledge for improving their own performance. In this line, Little (2010) reported that talent management results in applying new technologies and guiding individuals in his career path. Cantrell and Benton (2007) reported that talent management, via creating consistency of individuals' activities with business needs, doing activities in the best ways, getting helps from the staff in human resources management, creating clear and sustainable policies, and creating an appropriate environment for sharing information provide the grounds for improving organizational performance.

Findings regarding the relationship of open atmosphere and culture with career path of principals of high schools in Shahr-e-Kord indicate that there is no significant correlation between open atmosphere and culture and strength (professional energy), attraction (professional fascination), and devotion (dedication) of high school principals. Open atmosphere and culture probably results in a kind of organizational disorder which can result in the dispersion of talents and distort individuals from their career path. Therefore, of open atmosphere and culture cannot put individuals in their career paths.

\section{References}

Armstrong, M. (1993). Strategic human resources management. S. M. Arabi and O. Mahdiyeh (Trans.). Tehran: Cultural Research Institute.

AsheghHosseiniMehravani, M. et al. (2014). Investigating the relationship between talent management and organizational performance. Journal of Human Resources Management University of Imam Hussein, 6(1), S51-31.

Bethke -Langenegger, P \& Mahler,P \&Staffelbach, B. (2010). Effectiveness of Talent Management Strategies in Swiss Companies. Lehrstuhl Human Resource Management, Nr. $16,4-8$.

Bhatnagar, J. (2007). Talent Management Strategy of employee engagement in Indian ITES employees. Employee Relations, 29(6), 633-640. 
Cantrell, S., \& Benton, J. M. (2007). The fire essential Practices of a Talent multiplier. Business strategy series., 8(5), 358-364. http://dx.doi.org/10.1108/17515630710684475

Cheloha, R., \& Swain, J. (2005). Talent management system key to effective Succession planning .Canadian HR Reporter, 18(17), 5-7.

Ghaffari, A. et al. (2013). The Relationship between talent management in the performance of faculty members of University of Isfahan. Journal of General Administration, 5(3), 102-83.

Guy, M., \& Siems, D. (2009). Developing future talents. N. Jazani (Trans.). Tehran: Saramad. Hosseini, A. (2011). Talent management role in securing and retaining talented human resources. Journal of New Business and Economy, 24, 205-181.

Iles, P., Chuai, X., \& Preece, D. (2010). Talent Management and HRM in Multinational Companies in Beijing: Definitions, differences and drivers. Journal of World Business, 45(2), 179-189. http://dx.doi.org/10.1016/j.jwb.2009.09.014

Little, B. (2010). Talent Management and Its Technological Partners. Emerald Group Publishing Limited, 42(7), 389-393. http://dx.doi.org/10.1108/00197851011080360

Nouri, A. et al. (2010). The relationship between work engagement components with dimensions of organizational commitment. Journal of New Findings in Industrial /Organizational Psychology, 1(5), 5-9.

Salanova, M., Agut, S., \& Peiro, J. M. (2005). Linking organizational resources and workengagement to employee performance and customer loyalty: the mediation of service

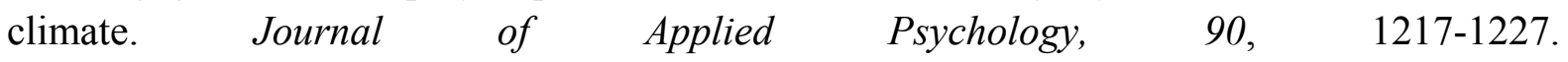
http://dx.doi.org/10.1037/0021-9010.90.6.1217

Schaufeli, W. B., Bakker, A. B., \& Sala nova, M. (2006). The measurement of work engagement with a short questionnaire: Across-national study. Educational and psychological Measurement, 66, 701-716. http://dx.doi.org/10.1177/0013164405282471

Tajjalizadeh, M. (2013). Investigating the relationship between intellectual capital and job engagement and job motivation among employees of education offices in Ahvaz. MA thesis. University of Isfahan. Faculty Psychology and Educational Sciences.

\section{Copyright Disclaimer}

Copyright reserved by the authors.

This article is an open-access article distributed under the terms and conditions of the Creative Commons Attribution license (http://creativecommons.org/licenses/by/3.0/). 